\title{
Assessment Issues of Sustainability of Rural Area Development Under Digitalization Conditions
}

\author{
Agibalov A.V.* \\ Voronezh State Agrarian University named after Emperor \\ Peter the Great \\ Voronezh, Russia \\ e-mail: agi-64@mail.ru
}

\author{
Zaporozhtseva L.A. \\ Voronezh State Agrarian University named after Emperor \\ Peter the Great \\ Voronezh, Russia \\ e-mail: ludan23@yandex.ru
}

\author{
Tkacheva Yu.V. \\ Voronezh State Agrarian University named after Emperor \\ Peter the Great \\ Voronezh, Russia \\ e-mail: julchen19@yandex.ru
}

\author{
Sabetova T.V. \\ Voronezh State Agrarian University named after Emperor \\ Peter the Great \\ Voronezh, Russia \\ e-mail: tsabetova@mail.ru
}

\author{
Tolstolutckii R.O. \\ Voronezh State Agrarian University named after Emperor Peter the Great, \\ Voronezh, Russia \\ e-mail: tolromol@mail.ru
}

\begin{abstract}
Sustainable development of rural areas in the current economic conditions is attracting close attention not only in Russia but throughout the world. At the same time, the problem of choosing indicators and the mechanism for assessing the dynamics of sustainable development of rural territories at each level is particularly urgent. The same discussion is caused by the need and the possibility of polycentric development of regions, differentiation of urban and rural areas, as well as the constituent entities of the Russian Federation in terms of development levels. The purpose of this study is to formulate a methodology for the sustainable development of rural areas and justify the efficiency of its practical use in the system of implementing regional and departmental programs and the potential of local self-government. The issues of digitalization of this process in the current economic conditions are of particular importance. In this regard, to assess the development of rural areas, the authors propose an approach that allows not only selecting key assessment indicators, but also defining the achieved and potentially achievable levels of development of a specific territory. The main approach for assessing the level of development of rural territories is chosen to be the scenario approach as the basis for differentiating the type of development of rural areas: highly sustainable, sustainable and unstable, which can also be used to monitor the path of long-term development, and the universality of the method allows it being applied to all parts of the country, regardless of their type and size. Moreover, the achievement of an inertial scenario within the framework of an unstable type of development is the basis for diagnosing the controllability of the territory's strategy at the appropriate level of structural organization.
\end{abstract}

Keywords - sustainable development, rural areas, scenario approach, assessment procedure, digitalization of economy.

\section{INTRODUCTION}

Over the past two decades, and with the joint efforts of science, business, and government, conditions have been formed for the development of local self-government. Based on it the system has been created to ensure the sustainable development of rural territories in the Russian Federation.

The purpose of the study is to formulate a procedure for assessing the sustainable development of rural areas. We consider it most appropriate to consider the rural territory as an object of research, taking into account its inclusion in the regional, regional and national system of relations. Consequently, the subject can be considered a system of economic, social, environmental relations at the district, regional, and state levels, ensuring the realization of the development opportunities of rural territories. In the work we apply the basis of thedata and legal acts of the Voronezh region and the Russian Federation. Agriculture is one of the priority sectors of the economy of the region in question, moreover, for many settlements in the region it is almost the only type of economic employment in the productive sector. The importance of agricultural production for the region is emphasized by more than double its growth over the period of 2011-2016. When considering the rural areas of the Voronezh region, it is necessary to take into account their various typologies: many of them are mixed and include urban areas, which gives a significant shift in the level of their socioeconomic development and the indicators describing them.

The hypothesis is the assumption that a high-quality methodology for assessing the sustainability of development is able to ensure the implementation of the best trajectory of the socio-economic development of rural territories, since it is not 
only a tool for analyzing the implementation, but also for adjusting priority parameters.

\section{MATERIALS AND METHODS}

Among the research methods for sustainable development of rural areas in theory and practice, the following techniques and methods are distinguished (table 1) [1,2].

TABLE I. DESCRIPTION OF THE TECHNIQUES AND METHODS OF RURAL AREA SUSTAINABLE DEVELOPMENT ASSESSMENT

\begin{tabular}{|l|l|}
\hline \multicolumn{1}{|c|}{$\begin{array}{c}\text { Technique or } \\
\text { method } \\
\text { description }\end{array}$} & \multicolumn{1}{c|}{ Technique or method task } \\
\hline $\begin{array}{l}\text { neoclassical } \\
\text { techniques and } \\
\text { methods }\end{array}$ & $\begin{array}{l}\text { base don't he cost models, aimed at the assessment of } \\
\text { the quality of rural area resource base reproduction }\end{array}$ \\
\hline $\begin{array}{l}\text { cluster analysis } \\
\text { techniques }\end{array}$ & $\begin{array}{l}\text { applicable in various scientific fields for cluster } \\
\text { definition, necessary for differentiation of the structural } \\
\text { elements of rural area sustainable development }\end{array}$ \\
\hline $\begin{array}{l}\text { discriminatory } \\
\text { analysis } \\
\text { instruments }\end{array}$ & for classifying functions and for prospective forecasting \\
\hline $\begin{array}{l}\text { additive analysis } \\
\text { methods }\end{array}$ & $\begin{array}{l}\text { promising from the point of view of forming the } \\
\text { integrated indicator for rural area sustainable } \\
\text { development, etc. }\end{array}$ \\
\hline $\begin{array}{l}\text { horizontal } \\
\text { analysis methods }\end{array}$ & $\begin{array}{l}\text { for assessing the dynamics of the ongoing changes and } \\
\text { their interconnection }\end{array}$ \\
\hline $\begin{array}{l}\text { factor } \\
\text { aggregation }\end{array}$ & $\begin{array}{l}\text { for indices during their transformation into particular } \\
\text { and integrated indicators }\end{array}$ \\
\hline $\begin{array}{l}\text { defining the } \\
\text { strength of } \\
\text { correlation } \\
\text { between the } \\
\text { calculated } \\
\text { indicators }\end{array}$ & $\begin{array}{l}\text { base don't he multidimensional quantitative description } \\
\text { of the studied object and the factors defining its } \\
\text { dynamics }\end{array}$ \\
\hline $\begin{array}{l}\text { defining the } \\
\text { reserves of the } \\
\text { relation system } \\
\text { development }\end{array}$ & $\begin{array}{l}\text { forms the ranges of variations of the rural area } \\
\text { development }\end{array}$ \\
\hline
\end{tabular}

According to certain scientists [3], the problem of ensuring the sustainable development of rural areas is complex, which must be solved on the basis of convergence of information technologies, especially relevant for the digital economy, management technologies of large business entities (mesoand macrolevels), as well as methods of system theory and system analysis.

Thepriority directions of the state policy for the period up to 2035 [4] in the field of sustainable development of rural areas are:

- improvement of the demographic situation. Its negative character is manifested both by the general tendency of rural population aging, and by the high dynamics of its natural growth and migration balance;

- provision of conditions for the development and diversification of the rural economy. In this case, the administration's efforts will be aimed at increasing the generated value added, employment, and the role of industrial production in the territory;

- improvement of the living standard of the rural population. At the heart of its growth is the reduction in the differentiation of the availability of vital services and the income level of the rural and urban population;

- improvement of the rural community to the development resources. This line of activities is provided by the growth of information flows and remote access to public services, the development and implementation of smart technologies;

- development of rational use of natural resources and improvement of environmental condition in the rural areas. It is aimed at the formation of mechanisms for the household waste management, care for nature, and the introduction of modern technologies for life support;

- increasing the efficiency of local self-government, including through strict subordination of powers of authorities of various levels;

- improvement of the statistical monitoring system and methodological support of the rural area development. The key event in this direction will primarily be the formation of a strategic development trajectory and its qualitative and quantitative parameters;

- organization of the training, reskilling, and personnel development. This will expand the horizons of employment and form the basis for the growth of labor productivity.

\section{RESULTS AND DISCUSSION}

The sustainable development of rural areas should be based on stable, balanced growth rates of both the national economy of the country as a whole and the agro-food complex, in particular [5].

Some researchers consider it necessary to analyze a number of socio-demographic and socio-economic indicators to assess the level of sustainable development of rural areas [6].

The position of other scientists [7] consists of interpreting the sustainable development of rural areas through the control of three elements - economic, environmental, and social. The highlighted most important parameters allow assessing the level of socio-economic development of rural areas and their prospects.

In the works of academic economists [8] the necessity of assessment the rural area sustainable development levels is traced, based in the indicators describing:

- change in the socio-economic potential of business entities in rural areas, which allows diagnosing the type of innovation and investment development;

- stimulation of population growth and employment, the factor of which is the diversification of activities through the formation of new industries in the countryside;

- providing rural residents with comfortable housing and basic, vital social services at the level of city standards; 
- protection and development of the specific national cultural and spiritual heritage;

- reduction of the negative impact of human activities and industrial production on the environment condition;

- improvement of the institutional structure of business entities based on the synergies of cooperation and integration, as well as widening thegovernmental support.

Consequently, the determining value in assessing the level of sustainability of the socio-economic development of rural territories is assigned to the labor resources and the demographic potential of these territories in the presence of positive dynamics of changes in the living standards of the rural population [9].

Ensuring sustainable socio-economic development of rural areas also implies a congruent growth of social, economic, ecological systems within a specific territorial unit [10]. The list of mentioned components is also supplemented with the production component [11].

The priority in the development of rural territories in the Voronezh region is the social component: infrastructure and landscaping.

Within the framework of the state program for the integrated development of rural territories, the Voronezh region involves the implementation of three directions (subprograms):

1. Analytic, regulatory, and procedural support of the complex development of rural areas with respect to:

departmental project "Provision of public monitoring of rural areas". The development and formation of an information and analytical resource concerning the state of rural territories, scientific and methodological support of the programme are provisioned.

- departmental target project "Information and procedural provision of rural area complex development". It is planned to carry out training activities in the constituent entities of the Russian Federation on project skills for implementing the initiative projects for the integrated development of rural areas, and to ensure that the rural population is informed about activities implemented under the program.

2. National measures for the integrated development of rural areas within:

- departmental project "Development of housing construction in rural areas and housing improvement". It is prescribed to provide social payments for housing construction to citizens working in the agro-industrial complex and living in rural areas, to provide subsidies to co-finance the expenditure obligations of municipalities for the construction (purchase) of housing provided to citizens living in rural areas, under a rental contract for housing, rural mortgage , preparation of sites for individual housing construction.
- departmental project "Promotion of rural population employment". It will provide training and reskilling for those employed in rural areas, attracting young specialists for employment in rural areas.

- departmental project "Rural area landscaping".

- departmental project "Development of utility and transport infrastructure of rural settlements". The construction of gas distribution networks, local water pipelines, the implementation of projects for the complex arrangement of sites for compact housing construction, the construction and reconstruction of roads are planned.

3. The modern look of rural areas is supposed to be ensured through implementation of:

- departmental target project "The modern look of rural areas". It is supposed to ensure the creation of comfortable conditions in rural areas by bringing the proportion of rural settlements with access to the information and telecommunication network to $100 \%$.

According to the review of departmental projects and departmental target programs selected by the Voronezh region within the framework of the implementation of the national program for the integrated development of rural territories, we have found that the priority in the development of rural territories in our region until 2025 will be economic (employment and income) and social (infrastructure and landscaping) components. Consequently, the assessment of the level of sustainable development of rural areas of the region should take into account the specifics of the selected development vector.

In order to determine the level of sustainable development of rural areas, scientists propose not only the selection of indicators, but also the determination of the rating, the socalled rating approach for ranking rural areas.

From our point of view, to ensure a qualitative assessment of the sustainable development level of rural areas, an approach is needed that allows not only selecting key assessment indicators, but also establishing the achieved and potentially achievable development levels for a specific territory.

We propose to use the scenario approach as the key approach for assessing the development level of rural territories, which allows strategic prediction of rural development options. Its essence is to assess the development trajectory in accordance to one of the three scenarios adopted by the strategy of socio-economic development of rural areas. The complex of implemented scenarios is represented by the target (optimistic), basic (moderate) and inertial (pessimistic) ones, to certain degree characterizing the development prospects of rural territories[12].

The target scenario, within the designated planning interval for the period till 2035, is the best option for the socioeconomic development of rural areas, ensuring the achievement of development priorities and goals outlined in Strategy-2035. This scenario is realizedunder the 
implementation of favorable macroeconomic trends in the steady growth of target socio-economic and environmentalinstitutional indicators of rural development, and the growth rate of the target (optimal) scenario will be higher than the specified base.

As we noted, the basic (moderate) scenario also implies an increase in targeted socio-economic and environmentalinstitutional indicators, but more moderate one. It focuses mainly on the efforts of the administration of the territorial level and does not imply significant positive or negative dynamics of the macroeconomic environment.

The inertial (pessimistic) scenario plays an important role in the mechanism for ensuring the sustainable development of rural territories. It is described by interruption of the trajectory of optimal and moderate development, where full and sufficient implementation of the target indicators of the socioeconomic and ecological-institutional development of rural areas is not possible due to administrative resources because of their deficiencyforreverse of the previously formed trends. The key feature of this scenario is the impossibility of maintaining the achieved level of socio-economic development, as well as maintaining positive growth dynamics.

The most preferable scenario of the system of the indicated options is the target one: it is aimed at increasing and buildup the potential of the subject, the formation of its flagship position in the ranking of rural territories. The formation of the vector of sustainable permanent strategic development, in turn, determines the attractiveness of the scenario for the population, investors, and administration.

In terms of its functional significance, the basic (moderate) scenario is transitional or intermediate with respect to the inertial and target: in theory, it has averaged indicators of pessimistic and optimistic options. However, the transition is not always evolutionary, smooth, and therefore does not have to be accompanied by obvious manifestations of a moderate scenario. In the theory and practice of economic systems, cases of a revolutionary, rapid, transition from a pessimistic to an optimistic scenario of development, without going out to basic guidelines, are considered.

Although the inertial (pessimistic) development option is the least oriented towards sustainable development, achieving the formation of indicators for this scenario is important in implementing the strategy for sustainable socio-economic development of rural areas. Its implementation already implies some kind of minimal controlled "development": if there is no growth dynamics, then there is a decrease in indicators in adverse conditions not lower than the set level, which is important under the current conditions.

It is worth emphasizing that the system of qualitative and quantitative characteristics of the socio-economic development scenarios and the assessment of the achievement of its goals is rather specific for each rural territory. It is documented in Strategy-2035 forthe socio-economic development.

So, using the scenario approach, we propose a proprietary procedure for assessing the sustainability of rural area development (figure 1):

1. Calculation of goal-oriented indicators of sustainable development of rural territories (socio-economic and environmental-institutional), consistent with the directions of the National program of the Russian Federation "Integrated development of rural territories" [[13]] and, if necessary, adjusted.

2. Assessment of the indicator values to establish the achievement of the parameters of one of the selected development scenarios (target, basic or inertial).

3. Definition of the level of rural area development:

- in case of achieving the parameters of the target scenario, the rural territory is characterized by a high level of development and "Highly sustainable development" is declared;

- up on achieving the parameters of the basic scenario, the rural territory is characterized by an average level of development and "Sustainable Development" is determined;

- up on achieving the parameters of the inertial scenario, the rural territory is characterized by a low level of development and "Unsustainable development" is defined;

- if even the parameters of the inertial scenario are not achieved, the rural territory is characterized by a crisis level of development and the "Stagnation" of the territory is declared: the stagnant state of the economy, accompanied by the increase in unemployment, decrease in wages and living standards.

Forecast of a realistic rural development scenario based on the assessment of the achieved sustainability level.

5. Estimation of the rate of sustainable development of rural areas based on the integrated indicator to determine the vector of development of rural areas.

Using the procedure for assessing the sustainability of development according to the scenario approach we have proposed is possible in the process of monitoring the implementation of strategic priorities for rural development, achieving goals and solving problems, and also with the aim of adjusting the Strategy in the framework of the current legislation. Moreover, this procedure is subject to digitalization and is capable of performing the embedded functionality automatically. 


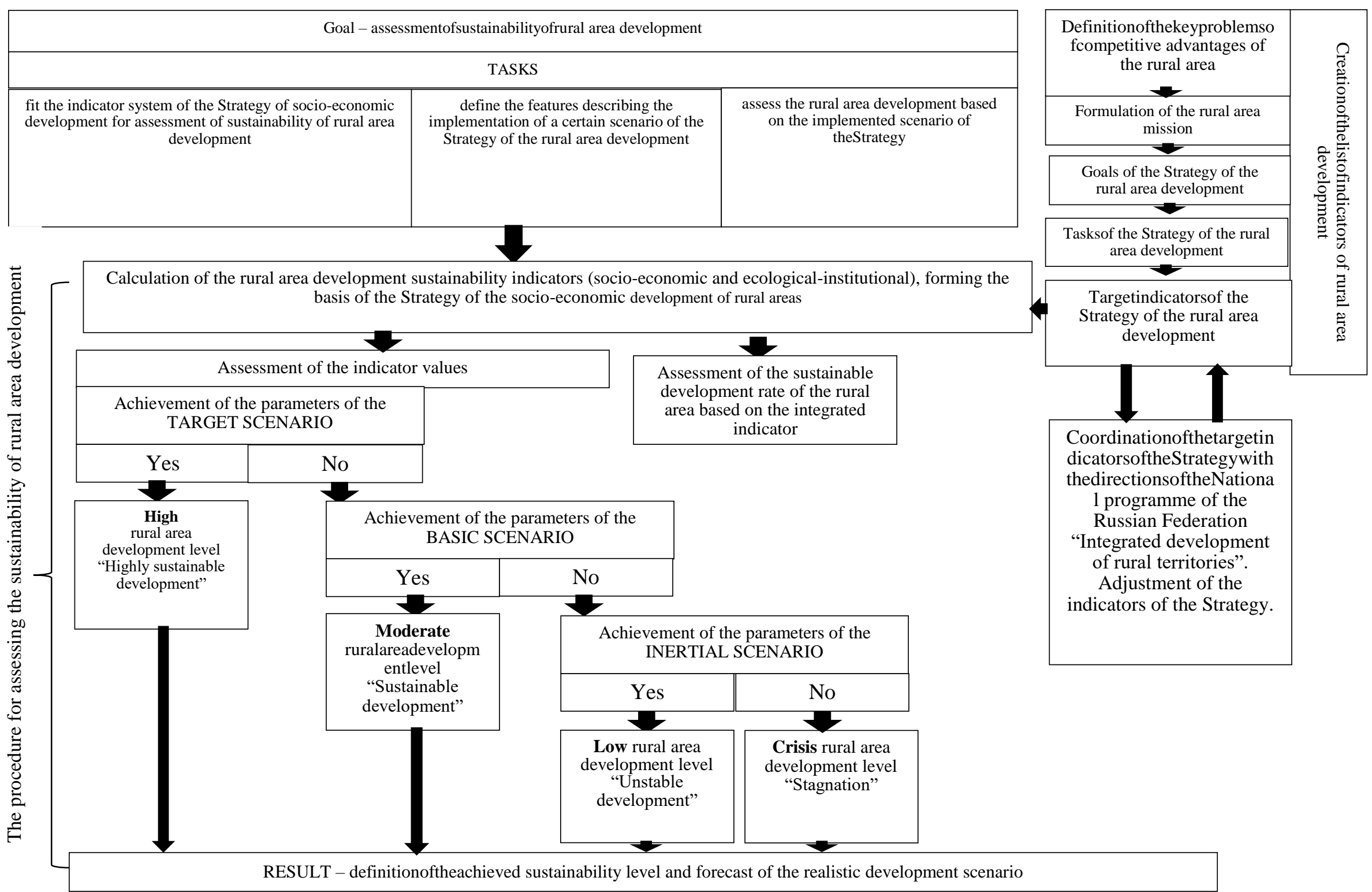

Fig. 1. The procedure for assessment of the rural area sustainable development (scenario approach) 


\section{CONCLUSION}

The assessment of the ruralarea development based on the scenario approach is necessary for achieving high level of sustainable development, that is, development according to the target scenario in the strategic perspective, which will help to ensure conditions for food independence of the country's population; qualitative transformation of agricultural entities and rural territories by creating conditions for ensuring the necessary level of production, innovation, investment, and social potentials for the full and effective use of labor, capital, and agricultural land, as well as increasing the satisfaction of the rural population with living conditions and income from working on land. A separate issue of the procedure is the subordination of assessments of the quality of rural area development of a higher level. So, the smallest territorial unit in the structure of which the implementation of a development strategy is possible is a rural settlement. Rural settlements are differentiated in terms of development level, quality of providing the population with benefits, available resources for investment and economic activity, remoteness or inclusion of urban areas. The level of differentiation is smoothed out by average district indicators, but at the regional level, this problem arises with renewed vigor and new emphasis aimed at subordinating the mechanisms of local, district, regional, and federal levels. Therefore, the basis for the successful implementation of the scenario approach at the regional level should be the realization of the main socially significant indicators for each of the districts, settlements, and cities that are part of the region. We believe the latter is true for the whole country, since at the centre of the strategy implementation is a person, human capital, as the basis for the development of our country for the period till 2035

\section{References}

[1] N.P. Agafonova, "Principles and methods of assessing the rural area sustainable development", Achievements of the modern sci. and ed. vol. 3, no. 2, pp. 113-115, 2017.
[2] V.P. Vasilyev, "Methods for assessing the economic stability of agricultural organizations", Terra Econ. , vol. 11, no. 3-3, pp. 50-54, 2013

[3] V.G. Bezborodov, I.Ju. Grishin, R.R. Timirgaleeva, "Cosmic monitoring of large agricultural region in favour of its sustainable development", Modern inform. Technol. and IT ed. , vol. 14, no. 4, pp. 1028-1034, 2018.

[4] "Concerning the approval of the Strategy of rural area sustainable development in the Russian Federation till 2030", Order of the Government of the Russian Federation dated 02 February 2015, no. 151-r (ver. Dated 13 January 2017). Retrieved from: http://www. consultant. ru (access date September 10 ${ }^{\text {th }}, 2019$ ).

[5] I.N. Turchaeva, V.M. Golovach, "Implementation of the national target programmes as a factor of rural area sustainable development", Bull. of Michurinsk state agrar. Univer. , no. 4, pp. 215-220, 2018.

[6] F.N. Dzodzieva, L.K. Bolatova, M.A. Bolatova, I.Z. Gagloeva "Indicators of territorial sustainable development", Schientific achievements - for agriculture: Proc. conf. , pp. 252-257, 2016.

[7] V.F. Vas'kin, A.I. Potvorov, "Rural area sustainable development as a factor of increasing the population's living standards", Bull. of Bryansk state agricult. Acad. , vol. 1, no. 53, pp. 64-68, 2016.

[8] A.I. Golubeva, V.I. Dorohova, A.N. Dugin, A.M. Suhovskaya "Formation of organizational and economic mechanism of sustainable development of regional rural areas", Bull. of agro-indust. complex of Verhnevolzh'e, vol. 1, no. 33, pp. 16-21, 2016.

[9] T.I. Nikitina, "Impact of demographic situation on the level of rural area sustainable development in the Chelyabinsk region", Bull. of Kursk state agricult. Acad. , no. 8, pp. 273-278, 2018.

[10] O.I. Panteleeva. "Indicatorsofrural area sustainabledevelopment: development and application". International scientific journal", 2010, no. 4 , pp. $49-54$.

[11] O.B. Shumakova, O.N. Kryukova, T.G. Mozzherina, "Provision of the sustainable development of agrarian economy based on the projectoriented approach to formation of the efficient agro-food market", Fundam. Res. , no. 12-2, pp. 293-298, 2018.

[12] A.V. Agibalov, L.A. Zaporozhtseva, D.S. Kleymenov, E.D. Kuznetsova A.A. Orehov, Ju.V. Tkacheva, "Strategic management of rural area sustainable development". Voronezh: VSAU, 2019, 175 p.

[13] "Integrated development and rural territories and making alterations in certain legal acts of the Government of the Russian Federation", Concerning the approval of the State programme of the Russian Federation. Order of the Government of the Russian Federation dated 31 May 2019, no. 696. Retrieved from: http://www. consultant. ru (access date 10 September 2019). 